Wright State University

CORE Scholar

6-2017

\title{
Animals and their Epibiota as Net Autotrophs: Size Scaling of Epibiotic Metabolism on Snail Shells
}

\author{
Nicole Lukens \\ Benjamin Kraemer \\ Vanessa Constant \\ Ellen J. Hamann \\ Ellinor Michel
}

See next page for additional authors

Follow this and additional works at: https://corescholar.libraries. wright.edu/biology

Part of the Biology Commons, and the Systems Biology Commons

\section{Repository Citation}

Lukens, N., Kraemer, B., Constant, V., Hamann, E. J., Michel, E., Socci, A. M., Vadeboncoeur, Y., \& McIntyre, P. B. (2017). Animals and their Epibiota as Net Autotrophs: Size Scaling of Epibiotic Metabolism on Snail Shells. Freshwater Science, 36 (2), 307-315.

https://corescholar.libraries.wright.edu/biology/566

This Article is brought to you for free and open access by the Biological Sciences at CORE Scholar. It has been accepted for inclusion in Biological Sciences Faculty Publications by an authorized administrator of CORE Scholar. For more information, please contact library-corescholar@wright.edu. 


\section{Authors}

Nicole Lukens, Benjamin Kraemer, Vanessa Constant, Ellen J. Hamann, Ellinor Michel, Anne M. Socci, Yvonne Vadeboncoeur, and Peter B. McIntyre 


\title{
Animals and their epibiota as net autotrophs: size scaling of epibiotic metabolism on snail shells
}

\author{
Nicole R. Lukens ${ }^{1,6}$, Benjamin M. Kraemer ${ }^{1,7}$, Vanessa Constant ${ }^{2,8}$, Ellen J. Hamann ${ }^{1,9}$, \\ Ellinor Michel ${ }^{3,10}$, Anne M. Socci ${ }^{4,11}$, Yvonne Vadeboncoeur ${ }^{5,12}$, and Peter B. McIntyre ${ }^{1,13}$ \\ ${ }^{1}$ Center for Limnology, University of Wisconsin-Madison, Madison, Wisconsin 53703 USA \\ ${ }^{2}$ Department of Integrative Biology, Oregon State University, Corvallis, Oregon 97331 USA \\ ${ }^{3}$ Life Sciences Department, Natural History Museum, London SW7 5BD UK \\ ${ }^{4}$ Foundation for Sustainable Forests, Spartansburg, Pennsylvania 16434 USA \\ ${ }^{5}$ Department of Biological Sciences, Wright State University, Dayton, Ohio 45435 USA
}

\begin{abstract}
Animals are heterotrophic by definition, but species from many taxonomic groups are hosts to epibiota that may alter their net metabolism. We tested the degree to which snail-shell epibiota can generate net ecosystem productivity for snails and their epibiota (snail-epibiota ecosystems; SEEs) after accounting for snail respiration. We focused on 3 species from the Lavigeria snail assemblage in Africa's Lake Tanganyika and quantified the scaling of SEE metabolism with shell size under light and dark conditions. The metabolism of snails and their epibiota shifted significantly across the size gradient. SEEs of large snails $(>20 \mathrm{~mm})$ were consistently autotrophic during the daytime, reflecting increases in shell algae as snails move into well-lit microhabitats after reaching a size refuge from predation by crabs. We extrapolated daytime individual SEE metabolism patterns to snail assemblages at 11 sites and found that SEEs range from heterotrophic to autotrophic in aggregate, reflecting spatial differences in size distributions. Our integration of organismal traits, species interactions, and assemblage structure reveals the important role of epibiota in organismal metabolism. Large epibiotic contributions to organismal metabolism could be widespread among animals that live in well-lit environments and fertilize their epibiota, but depend on the scaling of epibiotic and host metabolism with body size.
\end{abstract}

Key words: Lavigeria, Lake Tanganyika, primary production, respiration, co-evolution, microhabitat, assemblage, community

Animals are heterotrophic by definition, but species from many taxonomic groups host epibiota that may alter their net metabolism. For example, some caddisflies (Mooney et al. 2014), sloths (Suutari et al. 2010), and turtles (Neil 1954) have substantial epibiotic communities that include both primary producers (e.g., epiphytic algae) and heterotrophs (e.g., heterotrophic bacteria). The biomass of epibiota rarely exceeds that of the host, but small organisms (e.g., algae) have much higher mass-specific metabolic rates than larger organisms (Makarieva et al. 2008). Thus, primary production of epibiota could partially offset or even exceed the respiration of their animal host (Allen 1971, Pollard and Kogure 1993), potentially creating autotrophy of the host-epibiota ecosystem.

The relative role of epibiota in the net metabolism of host-epibiota ecosystems depends on the host's traits and its environment. For instance, sedentary animals generally have lower basal metabolic rates than more active animals, independent of size (Nagy and Montgomery 1980). In addition, a high ratio of host surface area to mass might enable epibiota to contribute substantially to metabolism, even achieving net autotrophy if sufficient area were available to epibiotic primary producers to offset respiration by their host. Hairy or spinous animals might be especially attractive hosts because their surface texture increases the surface area available to epibiota. Moreover, host excreta may fertilize epibiota on various time scales, as in cases of urine washing by primates (Milton 2010) or local enrichment of the water by aquatic organisms (Mooney et al. 2014). Environmental context also might mediate the metabolic balance between a host animal and its epibiota. Primary production per unit area generally increases with solar irradiance. Therefore, hosts that dwell in well-lit environments are likely to support substantial epibiotic primary producers. The relative contribution of epibiotic metabolism to net host-epibiota metabolism may be highest when the host is

E-mail addresses: ${ }^{6}$ nrlukens@gmail.com; ${ }^{7}$ To whom correspondence should be addressed, ben.m.kraemer@gmail.com; ${ }^{8}$ constanv@science.oregonstate .edu; ${ }^{9}$ ehamann@wisc.edu; ${ }^{10}$ e.michel@nhm.ac.uk; ${ }^{11}$ annie.m.socci@gmail.com; ${ }^{12}$ yvonne.vadeboncoeur@wright.edu; ${ }^{13}$ pmcintyre@wisc.edu 
sedentary, textured, and fertilizes the environment available to epibiota.

We evaluated the metabolic balance between snails and their epibiota in Lake Tanganyika, the oldest and deepest lake in Africa. Lake Tanganyika is exceptionally clear and nutrient poor. Its nearshore zone is highly productive with species-rich animal communities including a radiation of freshwater snails (West and Michel 2000), many of which are hosts for epibiota including algae, bryozoans, sponges, rotifers, and insects. Several abundant Lavigeria species achieve relatively large shell sizes by the standards of freshwater snails (>20-mm length), offering opportunities to quantify metabolic scaling with size. The benthic algae in the nearshore zone of Lake Tanganyika have exceptionally high productivity per unit biomass (O'Reilly 2006), in part because abundant and diverse grazers prevent periphyton accumulation (McIntyre et al. 2006). Our observations also suggest that snail shells frequently have more algal biomass per area than littoral rocks at the same depth. Thus, Lake Tanganyika's snails are an ideal model system for comparing epibiotic primary production to snail respiration to assess the degree to which snail-epibiota ecosystems (SEEs) can be autotrophic.

We measured the respiration and primary production of SEEs across a broad range of snail shell lengths (L) for 3 species of Lavigeria snails in the nearshore zone of Lake Tanganyika. We expected that SEE respiration (R) would scale with $\mathrm{L}^{2.54}$ based on the scaling of $\mathrm{R}$ with snail soft tissue mass $(M)\left(R \propto M^{0.75}\right.$; Gillooly et al. 2001) and the scaling of snail tissue mass with length $\left(M \propto \mathrm{L}^{3.38}\right)$. Furthermore, assuming that SEE gross primary production (GPP) scales linearly with snail shell area, we would expect SEE GPP to scale with $\mathrm{L}^{2}$ based on the surface area of a conical shell. Thus, we predicted that differential scaling of $\mathrm{R}$ and GPP with snail length would lead to changes in net metabolism with snail size. Last, we applied our size-based model of SEE metabolism to snail density and size distribution data from 11 nearshore sites to assess spatial variability in potential SEE metabolism in aggregate across snail assemblages. Merging survey data and metabolic measurements allowed us to use snail traits to estimate their collective role in littoral ecosystem metabolism.

\section{METHODS}

\section{Study system}

Lake Tanganyika is the $2^{\text {nd }}$-oldest and most voluminous lake in the world. The lake never fully mixes and has a permanently anoxic zone below 100- to 200-m depth. The lake ecosystem is under threat from a number of sources including climate change (O'Reilly et al. 2003, Tierney et al. 2010, Kraemer et al. 2015) and anthropogenic sedimentation, which reduces habitat availability for snails living on rocky substrates (Cohen et al. 1993, McIntyre et al. 2005).

Tanganyika is among the most species-rich lakes in the world, and most animal taxa in the lake are endemic (Vadeboncoeur et al. 2011) and part of species flocks (i.e., in situ evolutionary radiations of closely related species; Salzburger et al. 2014). The high endemicity of its fauna reflects the lake's size, age, and diversity of nearshore habitats. Lake Tanganyika has at least 81 species of gastropods (West et al. 2003), nearly all of which are endemic. The actual number of gastropod species in the lake may be double that described. Over 40 additional Lavigeria and 20 Paramelania species have been recognized from recent collections (Burgon et al. 2014). We focused on the 3 largest snail species that are sympatric and locally common on rock surfaces in $<10$-m water depth at shallow rocky nearshore habitats near Kigoma, Tanzania (Lavigeria nassa, Lavigeria grandis, and Lavigeria coronata; Fig. 1) (McIntyre et al. 2005). Pop-

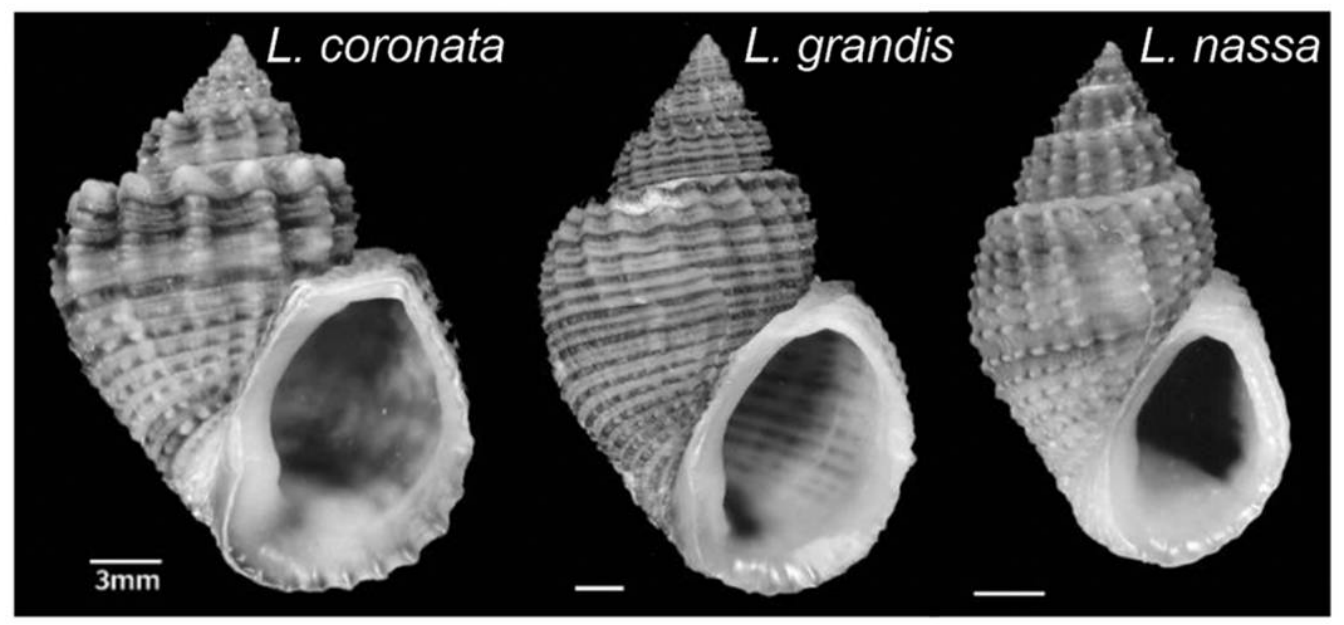

Figure 1. Empty shells cleaned of epibiota of Lavigeria coronata, Lavigeria grandis, and Lavigeria nassa (left to right). Scale bars $=$ $3 \mathrm{~mm}$. Lavigeria nassa shows scar in center of final whorl from a crab attack. 
ulation densities and size distributions of these and other species vary enormously among sites (McIntyre et al. 2005).

\section{Metabolism measurements}

We measured daytime metabolism of SEEs from $\sim 5 \mathrm{~m}$ depth at 2 rocky nearshore sites ( 3 and 6 in Fig. 2A) near Kigoma between 14 July and 10 August 2012. Snails used for the incubations were L. coronata (Bourguignat, 1888) ( $n=8$, all from site 3), L. nassa (Woodward, 1859) ( $n=$ 13 , all from site 3), and L. grandis (Smith, 1881) $(n=22$ from site $3, n=8$ from site 6 ). Immediately upon collection between 1000 and $1500 \mathrm{~h}$, we transferred each snail into its own clear plastic incubation chamber of lake water (114 $\mathrm{mL}$ ) suspended $1 \mathrm{~m}$ below the surface from a moored boat. We measured initial dissolved $\mathrm{O}_{2}$ levels after the snail re-emerged from its shell (1-5 min). Light measurements (Hobo Pendant; Onset Corporation, Bourne, Massachusetts) indicated that shading from the boat and the dis- solved $\mathrm{O}_{2}$ probe produced light levels inside the chamber that matched those typical at $5 \mathrm{~m}$ depth during the daytime when SEE metabolism incubations took place. We suspended a control chamber containing only lake water adjacent to the incubation chamber. To distinguish net SEE metabolism from snail and epibiota respiration, we randomly selected 28 snails for incubation in opaque chambers to eliminate epibiotic primary productivity while we incubated 23 snails in transparent chambers to measure net SEE daytime metabolism. We logged dissolved $\mathrm{O}_{2}$ and temperature every $30 \mathrm{~s}$ with an YSI ProODO meter (Yellow Springs Instruments, Yellow Springs, Ohio) with the sensor head sealed inside the chamber.

Incubations lasted $30 \mathrm{~min}$, unless the dissolved $\mathrm{O}_{2}$ fell below $4 \mathrm{mg} / \mathrm{L}$ (thereby stressing snails) or rose above $10 \mathrm{mg} / \mathrm{L}$ (enabling loss of $\mathrm{O}_{2}$ by outgassing). We calculated the daytime SEE $\mathrm{O}_{2}$ flux as the difference in change in dissolved $\mathrm{O}_{2}$ between the SEE and control incubations, standardized for incubation time and water volume. We used the differ-
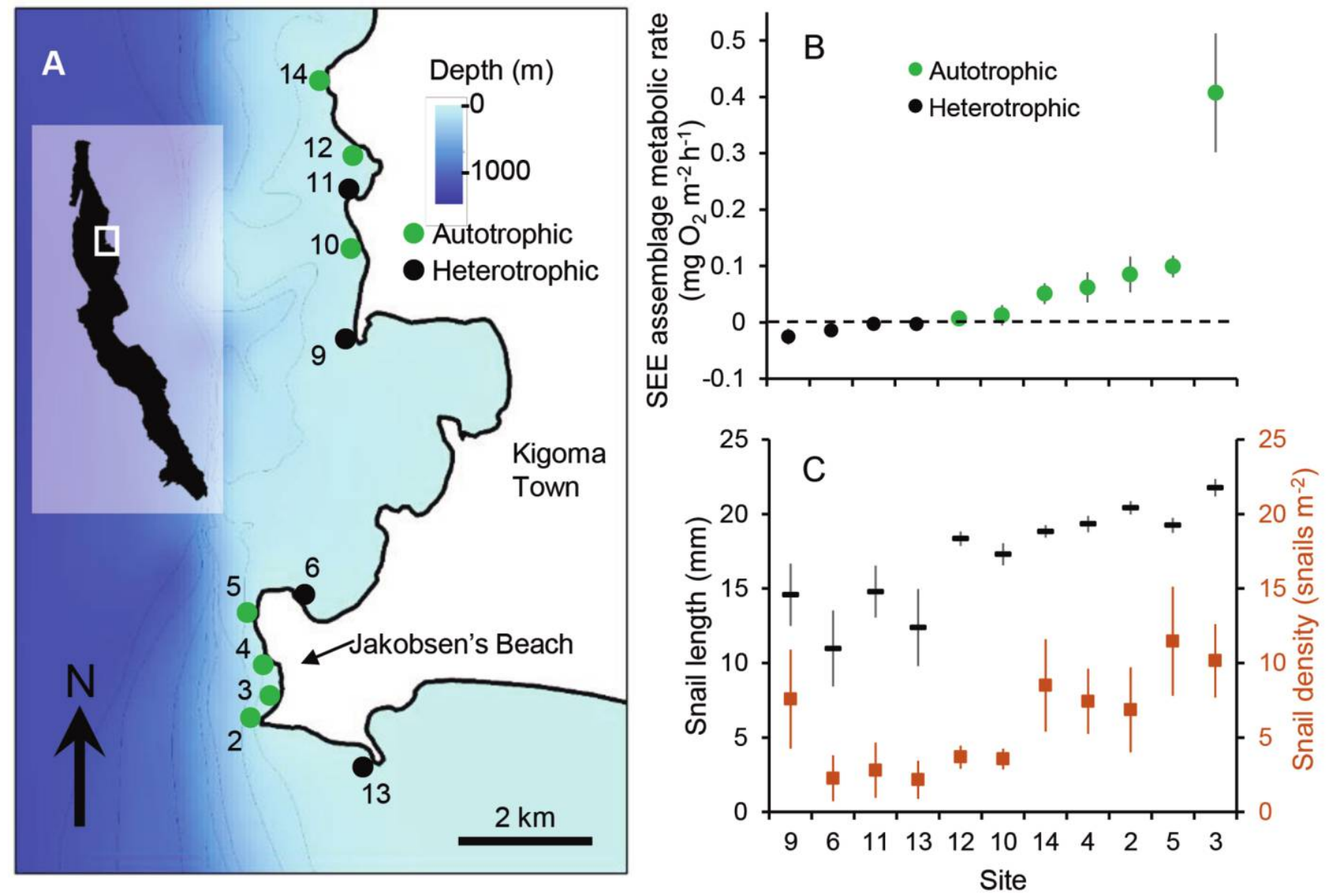

Figure 2. Survey sites in Lake Tanganyika at $5 \mathrm{~m}$ depth (A), mean ( $\pm 95 \% \mathrm{CI})$ snail epibiota ecosystem (SEE) net metabolic rate (B), and snail shell length and density $(\mathrm{C})$. Sites 3 and 6 were the focal sites where snails were taken for metabolism incubations. SEE net productivity estimates were extrapolated from the size-based models of SEE gross primary production and respiration. Sites in panels B and $\mathrm{C}$ are ordered by their net metabolic rate, but site numbers correspond to numbers in panel A. Sites 1 to 12 are the same as in work by Corman et al. (2010) with the addition of 2 sites (13 and 14). Sites 1, 7, and 8 were excluded from this analysis because of their proximity to human settlements. 
ence between the SEE and control incubations to remove the effect of background GPP and ER in the water in which snails were incubated. After each incubation, we measured the shell length $(\mathrm{L})$ along the coiling axis from the apex to the anterior-most edge of the aperture. We corrected the chamber volume for an approximation of the volume displaced by the snail $\left({ }^{4} /{ }_{3} \pi \mathrm{L}^{3}\right)$. These estimates of net metabolism were not integrated over a full day because we do not have nighttime measurements of SEE metabolism, which could differ from daytime rates.

The conditions of the SEE incubations reflected the underwater environmental conditions and snail populations found at $5-\mathrm{m}$ depth. The average water temperature inside snail incubation chambers was $26.56^{\circ} \mathrm{C}$ (range: $25.51-$ $27.45^{\circ} \mathrm{C}$ ), which was within the range of observed seasonal temperature variation in Lake Tanganyika. The range of lengths of incubated snails was 13 to $35 \mathrm{~mm}$, representing the full size range observed in our field surveys of these species from juveniles to adults. The median snail lengths for incubated L. grandis, L. nassa, and L. coronata were 21.8, 20.3 , and $27.6 \mathrm{~mm}$, respectively.

\section{Snail metabolism modeling}

For all analyses, we standardized daytime metabolic rates to $26.5^{\circ} \mathrm{C}$ using general, empirically derived relationships between temperature and benthic metabolism (YvonDurocher et al. 2010) and snail metabolism (Gillooly et al. 2001). This technique enabled us to compare rates directly without the influence of small differences in water temperature. Corrections were always minor. First, we used $\mathrm{R}$ data from the dark incubations to quantify the scaling of SEE $R$ with L. We used analysis of covariance (ANCOVA) to test whether the scaling of $\log _{10}(\mathrm{SEE} R)$ with $\log _{10}(\mathrm{~L})$ varied by snail species (for all 3 species) or by site (for L. grandis only). If we found no species or site effects, we pooled the data across species and site and used Theil-Sen's nonparametric regression (Theil 1950, Sen 1968, Peng et al. 2008) to estimate the relationship between $\log _{10}(\mathrm{SEE} R)$ and $\log _{10}(\mathrm{~L})$. We selected Theil-Sen's nonparametric regression because it is less sensitive than least squares regression to outliers. The slope coefficient for $\log _{10}(\mathrm{~L})$ in the Theil-Sen regression is the scaling exponent between $\mathrm{R}$ and $\mathrm{L}$ for SEEs. We used the $95 \%$ confidence interval (CI) to test our expectation that $\mathrm{R}$ scales with $\mathrm{L}^{2.54}$ based on metabolic scaling and shell geometry.

Second, we used SEE GPP data (standardized to $26.5^{\circ} \mathrm{C}$ ) to test the hypothesis that GPP scales with $\mathrm{L}^{2}$. We calculated SEE GPP by subtracting estimated SEE R (predicted from shell size; described above) from the net change in dissolved $\mathrm{O}_{2}$ during light incubations. This approach is analogous to using dark and light incubations to estimate GPP and $\mathrm{R}$ in the water column (Staehr et al. 2012). We used an analysis of covariance (ANCOVA) to test whether the scaling of SEE GPP with L differed across snail species (for all
3 species) or sites (for L. grandis only). If we found no effect of species or site, we used Theil-Sen's nonparametric regression to estimate the relationship between $\log _{10}$ (GPP) and $\log _{10}(\mathrm{~L})$. We used the $95 \% \mathrm{CI}$ for the slope coefficient to test our expectation that GPP scales with $\mathrm{L}^{2}$ based on shell surface area. All statistics were run with $\mathrm{mblm}$ and base packages in the software R (version 3.1.3; R Project for Statistical Computing, Vienna, Austria).

To assess whether changes in SEE GPP with shell size were attributable to epibiota, we quantified epibiotic biomass on a separate set of 14 L. grandis from site 3 in October 2015. We used a brass brush to gently scrub all epibiota from a shell, then filtered the resulting slurry onto a preweighed glass-fiber filter. We measured epibiotic dry mass after oven-drying filters $\left(60^{\circ} \mathrm{C}, 48 \mathrm{~h}\right)$. This measurement was based on the assumption that erosion of the mineral parts of the shell was minimal. We used Theil-Sen's nonparametric regression to estimate the relationship between $\log _{10}$ (epibiotic dry mass) and $\log _{10}(\mathrm{~L})$. We used the 95\% CI for the slope coefficient to test our expectation that epibiotic dry mass scales with $\mathrm{L}^{2}$ based on shell surface area.

\section{Snail densities and assemblage metabolism}

We used the size-scaling of individual SEE metabolism to estimate aggregate SEE metabolism of snail assemblages at 11 rocky littoral sites $(\sim 1 \mathrm{~km}$ between sites; see Corman et al. 2010). These sites are our long-term monitoring sites that receive little or no sediment loading. We avoided sites where sedimentation has shifted the size structure and species composition of the snail assemblage (McIntyre et al. 2005) and potentially has affected SEE metabolism. We quantified snail densities, species composition, and size distributions by collecting snails from 8 replicate quadrats (1- $\times 1$-m square, $\sim 5$-m spacing) at 5-m depth in JulyAugust 2012. We scrubbed each snail of its epibiota for identification, measured it, and checked for scars from crab predation attempts. We applied the fitted size-scaling model of SEE GPP and R to each L. grandis, L. nassa, and L. coronata observed in our quadrats to estimate aggregate metabolism associated with the snail assemblage. For each individual snail in the assemblage, we randomly selected a coefficient from the distribution of pairwise coefficients from the Theil-Sen method to account for uncertainty in scaling coefficients for GPP and R of SEEs. For these calculations, we assumed that water temperatures were uniform across sites $\left(26.5^{\circ} \mathrm{C}\right)$, in keeping with observations (Corman et al. 2010). We estimated the site means and 95\% CIs for site snail density, average snail length, and SEE metabolism by resampling 200 times with replacement from the 8 quadrat-level estimates of these variables.

\section{RESULTS}

SEEs were heterotrophic in dark and tended to be autotrophic in light conditions (all data from our study can be 
found in Appendix S1). Dissolved $\mathrm{O}_{2}$ concentrations declined relative to the control in all dark incubations (mean \pm SD: $-0.21 \pm 0.18 \mathrm{mg} \mathrm{O}_{2} / \mathrm{h}$ ) but increased in $67 \%$ of light incubations $\left(0.07 \pm 0.20 \mathrm{mg} \mathrm{O}_{2} / \mathrm{h}\right)$.

The size-scaling of SEE metabolism was only partially explained by simple size-scaling rules. Theil-Sen slopes indicated that $\mathrm{R}$ increased with $\mathrm{L}^{2.23}$ (Figs. $2 \mathrm{~B}, \mathrm{C}, 3$ ), and the 95\% CI for the scaling coefficient of $\mathrm{R}(1.71-2.83)$ included the hypothesized value of 2.54 . Thus, we did not find evidence to reject the null hypothesis that SEE R can be explained by simple allometric scaling rules. SEE GPP increased with $\mathrm{L}^{3.06}$ (Fig. 3), and the 95\% CI (2.63-4.10) did not include the hypothesized value of 2 . Snail epibiotic dry mass increased with $\mathrm{L}^{3.76}$, and the 95\% CI (3.23-4.00) for the scaling coefficient also did not include the hypothesized value of 2. Size-scaling of R and GPP of SEEs did not differ among snail species (ANCOVA, $p=0.16$ and $p=0.93$, respectively) or between sites (ANCOVA, $p=0.11$ and $p=$ 0.88 , respectively).

SEEs in the light incubations-which included both $\mathrm{R}$ and GPP processes-shifted gradually from heterotrophic to autotrophic with increasing snail length (Fig. 4A). The point at which SEEs switched from heterotrophic to autotrophic occurred at $\mathrm{L} \approx 20 \mathrm{~mm}$ (Fig. $4 \mathrm{~A}$ ), which is also the size at which we observed increases in epibiotic biomass on shells (Fig. 4B) and frequencies of shell scars from failed predation attempts by crabs from snail surveys (Fig. 4C). Predation scars occurred on 178 of 546 snails measured in the snail-assemblage surveys. Small snails $(\mathrm{L}<15 \mathrm{~mm})$ rarely had scars, whereas snails $>20 \mathrm{~mm}$ were frequently scarred (Fig. 4C).

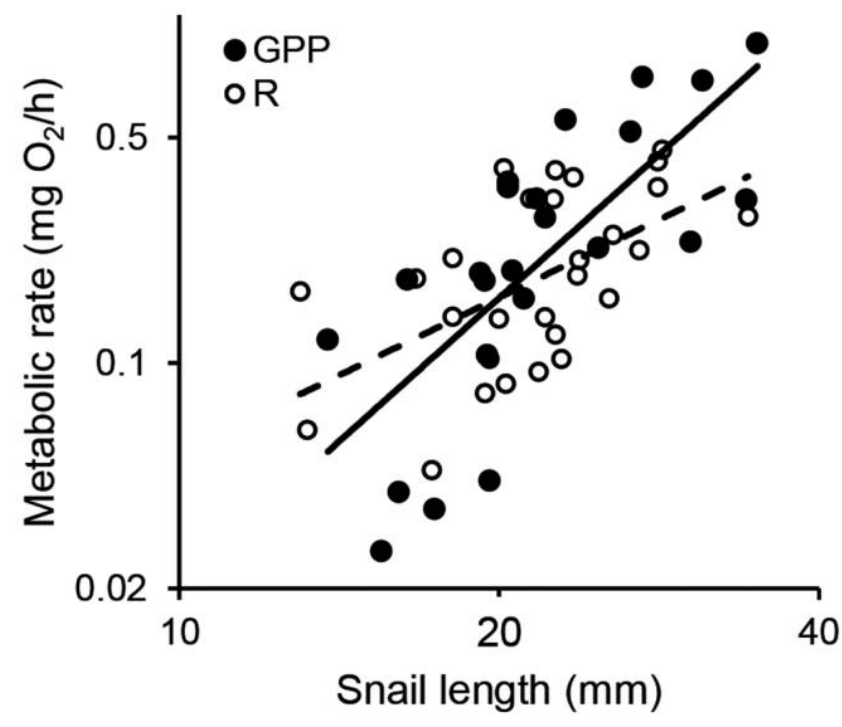

Figure 3. Respiration ( $\mathrm{R}$ ) and gross primary production (GPP) of Lavigeria snails and their epibiota on a gradient of snail size. Axes are on a log scale. Lines are median-based bestfit lines for GPP (scaling coefficient $=3.06$ ) and R (scaling coefficient $=2.23$ ).
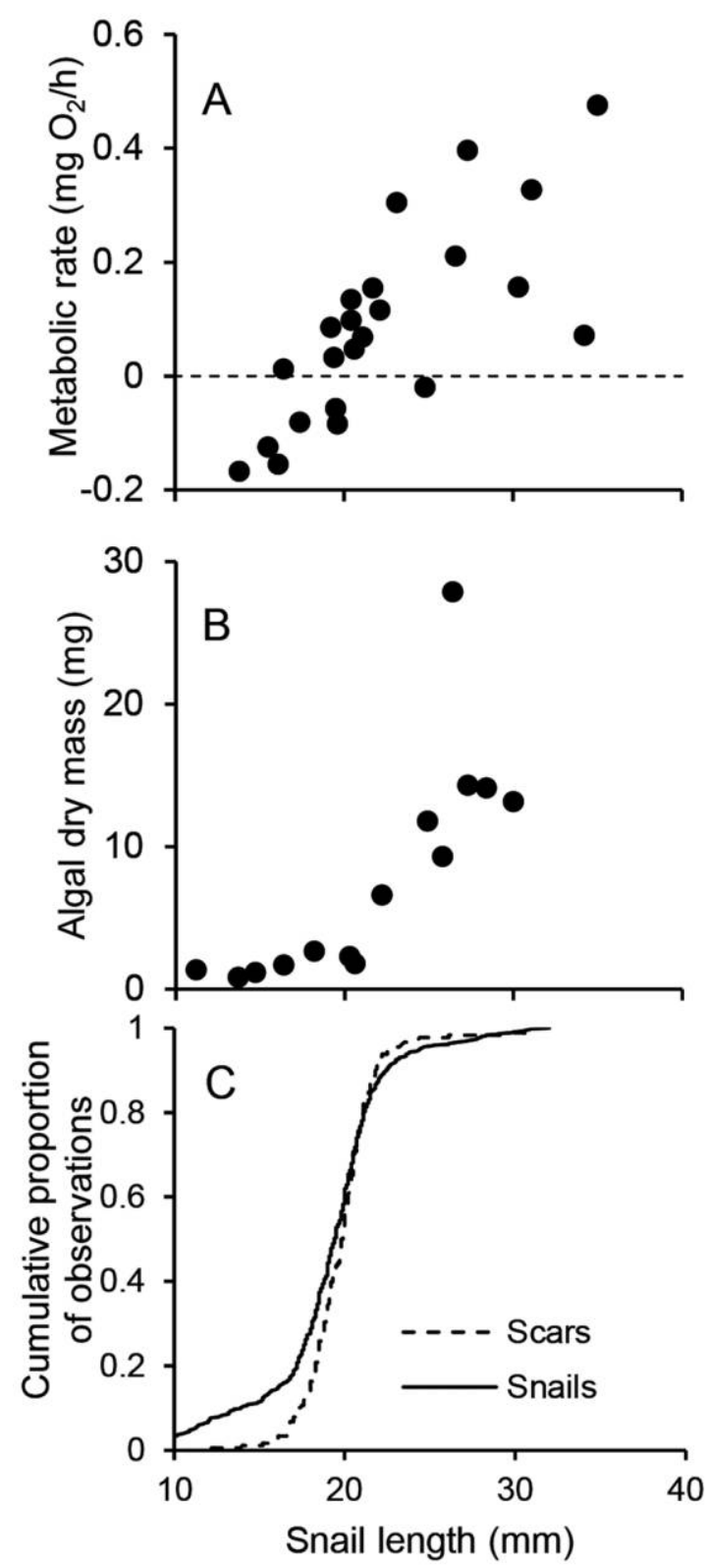

Figure 4. Net metabolic rate (A), epibiotic dry mass (on Lavigeria grandis shells only) (B), and presence of scars from crab attacks on snail shells $(C)$ as a function of snail length. Metabolic rate is the difference between Lavigeria snailepibiota ecosystem gross primary production and respiration. The solid black line in panel $\mathrm{C}$ represents the cumulative size frequency distribution for 547 snails collected during the site survey. The dashed black line represents the cumulative proportion of scars from crab attacks across the same snail size distribution (178 of 547 snails had $\geq 1$ scar).

Results obtained by applying the size-scaling equations for SEE GPP and R to the size frequency distributions for L. nassa, L. grandis, and L. coronata from each site suggest that snail assemblages at 7 of 11 sites are autotrophic at $5 \mathrm{~m}$ during the daytime (Fig. 2B). Across sites, assemblage-level 
daytime net metabolism of SEEs ranged from $-0.04 \mathrm{mg}$ $\mathrm{O}_{2} \mathrm{~h}^{-1} \mathrm{~m}^{-2}$ to $0.47 \mathrm{mg} \mathrm{O}_{2} \mathrm{~h}^{-1} \mathrm{~m}^{-2}$ (mean: $0.06 \mathrm{mg}$ $\mathrm{O}_{2} \mathrm{~h}^{-1} \mathrm{~m}^{-2}$; Fig. 2B). Densities of the 3 focal species ranged from 2.2 to 11.5 snails $/ \mathrm{m}^{2}$, and average $\mathrm{L}$ ranged from 11.0 to $21.8 \mathrm{~mm}$ across the 11 survey sites (Fig. 2C). Sites with higher density tended to have larger snails. Lavigeria nassa and $L$. grandis were found at all sites, but L. coronata was found at only 3 sites (sites 2, 3, and 11; Fig. 2A). Lavigeria coronata tended to be larger on average than the other species. Median snail lengths for L. grandis, L. nassa, and L. coronata in the site survey were 19.0,19.4, and $27.8 \mathrm{~mm}$, respectively.

\section{DISCUSSION}

The relationship between SEE R and L matches general predictions of metabolic scaling with soft tissue mass for large Lavigeria snails in Lake Tanganyika, suggesting that epibiotic R plays a minimal role in SEE metabolism. However, epibiotic GPP plays a large role in SEE metabolism and drives autotrophy at large snail size. GPP also scales more steeply with $L$ than what would be expected from simple scaling assumptions and gives rise to a shift from daytime heterotrophy to daytime autotrophy as snails grow. The point at which SEEs change from heterotrophy to autotrophy occurs at $\mathrm{L} \approx 20 \mathrm{~mm}$, which is approximately the size at which snails begin accumulating epibiota and appear to reach a size refuge from predatory crabs (Fig. 4C).

We speculate that the shift from heterotrophy to autotrophy of SEEs as snails grow reflects ontogenetic shifts in microhabitat use by snails that is driven by the risk of crab predation (West and Cohen 1994, 1996). Several species of endemic crabs have robust molariform dentition on their chelae that enable them to crush snail shells (Marijnissen et al. 2008). Strong selective pressure from crabs is thought to be responsible for thickness, crossed-lamellar layer microstructure, and diverse shell sculpturing that differ between many Tanganyikan snails and freshwater snails elsewhere (West and Cohen 1996). Predation trials suggest that Lavigeria $>20 \mathrm{~mm}$ generally withstand attacks from crabs, but smaller snails usually are killed (West et al. 1991). The risk of predation by crustaceans leads to microhabitat shifts in many snail species (Hadlock 1983, Alexander and Covich 1991, DeWitt et al. 1999, Trussell et al. 2003) and apparently in Tanganyikan snails as well. Juvenile Lavigeria often are found under rocks or in cracks where they can avoid crabs, whereas larger conspecifics are found almost exclusively in the open where they are exposed to crabs (West et al. 1991). Thus, the shells of juvenile snails may provide poor habitat for epiphytic algae because they occupy poorly lit microhabitats. Only when snails are large enough to withstand most crab attacks (Fig. 4C) do epibiota accrue on their shells (Fig. 4B). Our metabolic data suggest that increasing epibiotic biomass in turn gives rise to a shift from heterotrophy to autotrophy of SEEs as snails shift micro- habitats (Fig. 4B). This series of correlations leads us to surmise that a causal chain links the coevolutionary arms race between crabs and snails in Lake Tanganyika (West et al. 1991) to the role of epibiota in snail metabolism, mediated by adaptive microhabitat shifts that limit algal growth on snail shells.

Nutrients excreted and egested by snails are likely to enhance epibiotic GPP on their shells. Epibiota growing on other slow-moving animals benefit from the nutrients that their hosts excrete (Ings et al. 2012, Mooney et al. 2014). Because of their proximity, epibiota may have ready access to the nutrients that snails release as waste, especially below the wave surge zone (typically the upper 3-4 $\mathrm{m}$ of the water column) where water mass movements are less likely to sweep away excreted and egested nutrients. Nutrient recycling in the form of feces and liquid excretion may create miniature biogeochemical hotspots in freshwater ecosystems (McIntyre et al. 2008), which could be critical for fueling primary production in a nutrient-scarce environment like Lake Tanganyika (McIntyre et al. 2006). Some snails secrete mucus to deter predators, and mucus also could be a nutrient source for epibiota (Coffroth 1990). The combination of light limitation of primary production on juvenile snails and nutrient-enrichment of algal growth on adult snails may be responsible for the high size-scaling exponent for SEE GPP (3.06) and epibiota dry mass (3.76).

The 3 species that we studied differ in their degree of shell sculpturing (Fig. 1) and, thus, potentially the surface area available to epibiota. Despite interspecific differences in shell sculpturing, species identity did not significantly affect the size scaling of SEE GPP. Snails with spines or highly raised shell sculpturing could provide additional substrate for algal colonization and growth and a structural refuge for epibiota from grazing (Feifarek 1987, Abbott and Bergey 2007). Stronger tests of the effect of shell sculpturing on epibiotic GPP could include larger sample sizes or individuals with more disparate shell types. Snail species from Lake Tanganyika span a wide range in the degree of shell sculpturing. Thus, Tanganyika's sympatric snail species could provide an ideal system for future work to disentangle the effects of shell sculpture from other influences on SEE metabolism.

We were unable to estimate daily metabolism of SEEs because our light-dark incubations were conducted only during daylight hours. Snail $\mathrm{R}$ is likely to vary with diel cycles in activity and feeding, so our data may not be applicable throughout a 24-h period. Future tests of whether SEEs are heterotrophic or autotrophic when integrated over the full daily cycle will depend on the diel variability in SEE GPP and R. Our calculations suggest that snails with L > $20 \mathrm{~mm}$ were autotrophic during the day, but integrating over the full daily light cycle (assuming $12 \mathrm{~h}$ of GPP and $24 \mathrm{~h}$ of R per day) would create heterotrophy of SEEs at the individual level. However, if daytime SEE R exceeds nighttime SEE $R$ because snails decrease their activity to avoid 
nocturnal predators (Sih and McCarthy 2002), or if SEE $\mathrm{R}$ depends partially on contemporaneously produced organic C (Sandeen et al. 1954, Reddy et al. 1978, Tobias and Böhlke 2007, Staehr et al. 2010), then extrapolating to the full daily light cycle based on daytime SEE R would overestimate daily SEE R. If nighttime SEE R were $<60 \%$ of daytime SEE R, some large individual SEEs ( $\mathrm{L}>25 \mathrm{~mm}$ ) might still be autotrophic even over the full daily cycle.

Extrapolating individual daytime SEE metabolism to populations of our 3 focal species at 11 sites suggests $10 \times$ differences in daytime aggregate SEE metabolism. The shift from daytime heterotrophy to daytime autotrophy along the gradient of individual snail sizes was echoed by a similar shift at the assemblage level. Sites where Lavigeria had small average sizes were estimated to have strongly heterotrophic SEEs even during the daytime, whereas those at sites with larger snails tended to be balanced or marginally autotrophic when summing across SEEs. This pattern was most pronounced at site 3 , where the snail assemblage is relatively lacking small snails (whose SEE is heterotrophic even during the day) and comprises the largest species (L. coronata) and large individuals of the other species.

Our extrapolations to the assemblage level have several limitations. We assumed no differences in the metabolism of SEEs among sites because we observed comparable size scaling at the 2 sites where measurements were taken. However, algal biomass on rock surfaces varies considerably among the 11 sites used for extrapolation (Meyer et al. 2011, Vadeboncoeur et al. 2014), so epibiotic biomass on snail shells also might differ. In addition, algal biomass, GPP, and $\mathrm{R}$ and ambient light levels shift strongly with depth at any given site (Vadeboncoeur et al. 2014). We might expect stronger autotrophy of SEEs at depths $<5 \mathrm{~m}$ because of higher light availability, unless epibiotic primary producers become photoinhibited. Density, assemblage composition, and size distribution of snails also shift with depth (McIntyre et al. 2005), which would affect aggregate SEE metabolism of the snail assemblage. Last, our calculations focus only on 3 large-bodied Lavigeria species that make up most of snail biomass at most sites, but at least 3 to 4 additional species usually are present. We suspect that other species would show either higher (Lavigeria species J; West et al. 2003) or lower (Reymondia hori, Spekia zonata, Vinundui guillemi) GPP of SEEs than our focal species based on visible differences in epibiotic biomass. Thus, further work will be necessary to fully assess net metabolism of SEEs for the entire snail community across depths or sites.

Placing our extrapolations of the net metabolism of SEEs in a broader context, snails clearly play a minor role in littoral ecosystem metabolism. Over the period from June 2012-August 2013, we estimated average ecosystemlevel R and GPP at 1 of our nearshore study sites (site 3) to be 103 and $104 \mathrm{mg} \mathrm{O}_{2} \mathrm{~h}^{-1} \mathrm{~m}^{-2}$, respectively. Thus, daytime SEE GPP and R make up $<1 \%$ of total ecosystem me- tabolism at that site. Given the small proportion of rocky habitat covered by snails at all of our survey sites, their minimal role in whole-ecosystem metabolism is not surprising despite the evidence for metabolic rates of SEEs that are disproportionately high for their area. Our study supports the general conclusion that microbes and algae that are not attached to snails are responsible for most littoral ecosystem C fluxes.

Snails in Lake Tanganyika face several anthropogenic stressors that could modify the net metabolism of SEEs (Glaeser and Overmann 2003). At individual sites, anthropogenic sedimentation causes mortality (Donohue and Irvine 2003), alters species interactions (McIntyre et al. 2005), and shifts the size distribution of snails (McIntyre et al. 2005), any of which could affect SEE metabolism. The surface of Lake Tanganyika has warmed by $\sim 1.4^{\circ} \mathrm{C}$ over the last century (Kraemer et al. 2015), which may have increased SEE metabolic rates because of the temperature dependence of metabolism (Gillooly et al. 2001). The variability of temperature over our incubations was not sufficient to test its effect on SEE metabolism, but the possibility of differential effects of warming on SEE GPP vs $\mathrm{R}$ is worth exploring (Kraemer et al. 2016).

Our study provides insight into the role that epibiotic primary producers can play in offsetting the metabolic demands of animals at the organismal and ecosystem levels. Large snails are autotrophic when their epibiota are included in measurements of daytime metabolic rates under high light availability. The switch in SEE metabolic balance at $\sim 20-\mathrm{mm} \mathrm{L}$ appears to arise from greater epibiotic biomass as snails shift from concealed, aphotic microhabitats to fully illuminated rock surfaces as they reach a size refuge from predatory crabs. Whether our finding of daytime autotrophy of SEEs applies to other metazoans and their epibiota will depend on the characteristics of the host and the environment in which it lives. Slow-moving hosts with large surface-area-to-mass ratios that provide recycled nutrients for epibiota and live in well-lit environments are the most promising candidates for epibiotic GPP to offset host R. A variety of invertebrates with shells or cases, aquatic turtles, and crocodilians may fulfill these conditions. Thus, autotrophy of organismal ecosystems is unlikely to be limited to snails in Lake Tanganyika but, rather, is plausible for a variety of other taxa and ecosystem contexts.

\section{ACKNOWLEDGEMENTS}

Author contributions: NRL and BMK designed the study, performed all analyses, and wrote the manuscript. BMK, AS, EM, PBM, EJH, and VC collected all data. AS, EM, PBM, EJH, YV, and $\mathrm{VC}$ provided feedback on the manuscript.

Assistance with field work was provided by TAFIRI-Kigoma. We extend special thanks to Ishmael Kimirei, Mupape Mukuli, Hagai John, and Aniset Razalo. Research clearance was granted by the University of Dar es Salaam and facilitated by Rashid Tamatamah. Inspiration for this study came from Sam Drerup and 
Caroline Rost. We thank Jonathan Todd for comments on the draft manuscript. We are grateful for research funding from the National Science Foundation (DEB-1030242 and DEB-0842253) and a Packard Fellowship in Science and Engineering. We thank Associate Editor Robert Hall and 1 anonymous referee for constructive feedback that led to substantial improvements to the manuscript.

\section{LITERATURE CITED}

Abbott, L. L., and E. A. Bergey. 2007. Why are there few algae on snail shells? The effects of grazing, nutrients and shell chemistry on the algae on shells of Helisoma trivolvis. Freshwater Biology 52:2112-2120.

Alexander, J. E., and A. P. Covich. 1991. Predation risk and avoidance behavior in two freshwater snails. Biological Bulletin 180: 387-393.

Allen, H. L. 1971. Primary productivity, chemo-organotrophy, and nutritional interactions of epiphytic algae and bacteria on macrophytes in the littoral of a lake. Ecological Monographs 41:97-127.

Burgon, J. D., J. A. Todd, and E. Michel. 2014. Species diversity of Paramelania from Lake Tanganyika, East Africa-unifying molecular, conchological, radular and distribution data. Malacologist 63:7-9.

Coffroth, M. A. 1990. Mucous sheet formation on poritid corals: an evaluation of coral mucus as a nutrient source on reefs. Marine Biology 105:39-49.

Cohen, A. S., R. Bills, C. Z. Cocquyt, and A. G. Caljon. 1993. The impact of sediment pollution on biodiversity in Lake Tanganyika. Conservation Biology 7:667-677.

Corman, J. R., P. B. McIntyre, B. Kuboja, W. Mbemba, D. Fink, C. W. Wheeler, C. Gans, E. Michel, and A. S. Flecker. 2010. Upwelling couples chemical and biological dynamics across the littoral and pelagic zones of Lake Tanganyika, East Africa. Limnology and Oceanography 55:214-224.

DeWitt, T. J., A. Sih, and J. A. Hucko. 1999. Trait compensation and cospecialization in a freshwater snail: size, shape and antipredator behaviour. Animal Behaviour 58:397-407.

Donohue, I., and K. Irvine. 2003. Effects of sediment particle size composition on survivorship of benthic invertebrates from Lake Tanganyika, Africa. Archiv für Hydrobiologie 157:131144.

Feifarek, B. 1987. Spines and epibionts as antipredator defenses in the thorny oyster Spondylus americanus Hermann. Lournal of Experimental Marine Biology and Ecology 105:39-56.

Gillooly, J. F., J. H. Brown, G. B. West, V. M. Savage, and E. L. Charnov. 2001. Effects of size and temperature on metabolic rate. Science 293:2248-2251.

Glaeser, J., and J. Overmann. 2003. The significance of organic carbon compounds for in situ metabolism and chemotaxis of phototrophic consortia. Environmental Microbiology 5:10531063.

Hadlock, R. 1983. Alarm response of the intertidal snail Littorina littorea (L.) to predation by the crab Carcinus maenas (L.). Biological Bulletin 159:269-279.

Ings, N. L., A. G. Hildrew, and J. Grey. 2012. "House and garden": larval galleries enhance resource availability for a sedentary caddisfly. Freshwater Biology 57:2526-2538.
Kraemer, B. M., S. Chandra, A. I. Dell, M. Dix, E. Kuusisto, D. M. Livingstone, S. G. Schladow, E. Silow, L. M. Sitoki, R. Tamatamah, and P. B. McIntyre. 2016. Global patterns in lake ecosystem responses to warming based on the temperature dependence of metabolism. Global Change Biology (in press). doi: 10.1111/gcb.13459

Kraemer, B. M., S. Hook, T. Huttula, P. Kotilainen, C. M. O'Reilly, A. Peltonen, P.-D. Plisnier, J. Sarvala, R. Tamatamah, Y. Vadeboncoeur, B. Wehrli, and P. B. McIntyre. 2015. Century-long warming trends in the upper water column of Lake Tanganyika. PLoS ONE 10:e132490.

Makarieva, A. M., V. G. Gorshkov, B.-L. Li, S. L. Chown, P. B. Reich, and V. M. Gavrilov. 2008. Mean mass-specific metabolic rates are strikingly similar across life's major domains: evidence for life's metabolic optimum. Proceedings of the National Academv of Sciences of the United States of America 105:16994-16999.

Marijnissen, S. A. E., E. Michel, D. F. R. Cleary, and P. B. McIntyre. 2008. Ecology and conservation status of endemic freshwater crabs in Lake Tanganyika, Africa. Biodiversity and Conservation 18:1555-1573.

McIntyre, P. B., A. S. Flecker, M. J. Vanni, J. M. Hood, B. W. Taylor, and S. A. Thomas. 2008. Fish distributions and nutrient cycling in streams: can fish create biogeochemical hotspots? Ecology 89:2335-2346.

McIntyre, P. B., E. Michel, K. France, A. Rivers, P. Hakizimana, and A. S. Cohen. 2005. Individual- and assemblage-level effects of anthropogenic sedimentation on snails in Lake Tanganyika. Conservation Biology 19:171-181.

McIntyre, P. B., E. Michel, and M. Olsgard. 2006. Top-down and bottom-up controls on periphyton biomass and productivity in Lake Tanganyika. Limnology and Oceanography 51:15141523.

Meyer, J. R., E. Michel, P. B. McIntyre, B. E. Huntington, D. J. Long, and G. Lara. 2011. Scale-dependent processes of community assembly in an African rift lake. Freshwater Biology 56:2082-2093.

Milton, K. 2010. Urine washing behavior in the woolly spider monkey (Brachyteles arachnoides). Ethology 67:154-160.

Mooney, R. J., E. A. Strauss, and R. J. Haro. 2014. Nutrient recycling by caddisflies alleviates phosphorus limitation in case periphyton. Freshwater Science 33:1086-1092.

Nagy, K. A., and G. G. Montgomery. 1980. Field metabolic rate, water flux, and food consumption in three-toed sloths (Bradypus variegatus). Iournal of Mammalogy 61:465-472.

Neil, W. 1954. Algae on turtles: some additional considerations. Ecology 35:581-584.

O'Reilly, C. M. 2006. Seasonal dynamics of periphyton in a large tropical lake. Hydrobiologia 553:293-301.

O’Reilly, C. M., S. R. Alin, P.-D. Plisnier, A. S. Cohen, and B. A. McKee. 2003. Climate change decreases aquatic ecosystem productivity of Lake Tanganyika, Africa. Nature 424:766-768.

Peng, H., S. Wang, and X. Wang. 2008. Consistency and asymptotic distribution of the Theil-Sen estimator. Journal of Statistical Planning and Inference 138:1836-1850.

Pollard, P., and K. Kogure. 1993. The role of epiphytic and epibenthic algal productivity in a tropical seagrass, Syringodium isoetifolium (Aschers.) Dandy, community. Marine and Freshwater Research 44:141-154. 
Reddy, G. R., T. P. Kumar, P. M. Mohan, and K. S. Babu. 1978. Diurnal variations in physiological activities in the garden snail, Cryptozona ligulata. Journal of Comparative Physiology 125:59-66.

Salzburger, W., B. Van Bocxlaer, and A. S. Cohen. 2014. Ecology and evolution of the African Great Lakes and their faunas. Annual Review of Ecology, Evolution, and Svstematics 45:519-545.

Sandeen, M., G. Stephens, and F. Brown. 1954. Persistent daily and tidal rhythms of oxygen consumption in two species of marine snails. Physiological Zoology 27:350-356.

Sen, P. K. 1968. Estimates of the regression coefficient based on Kendall's tau. Iournal of the American Statistical Association 63:1379-1389.

Sih, A., and T. McCarthy. 2002. Prey responses to pulses of risk and safety: testing the risk allocation hypothesis. Animal Behaviour 63:437-443.

Staehr, P. A., D. Bade, M. C. Van de Bogert, G. R. Koch, C. Williamson, P. Hanson, J. J. Cole, and T. Kratz. 2010. Lake metabolism and the diel oxygen technique: state of the science. Limnology and Oceanographv: Methods 8:628-644.

Staehr, P. A., J. M. Testa, W. M. Kemp, J. J. Cole, K. Sand-Jensen, and S. V. Smith. 2012. The metabolism of aquatic ecosystems: history, applications, and future challenges. Aquatic Sciences 74:15-29.

Suutari, M., M. Majaneva, D. P. Fewer, B. Voirin, A. Aiello, T. Friedl, A. G. Chiarello, and J. Blomster. 2010. Molecular evidence for a diverse green algal community growing in the hair of sloths and a specific association with Trichophilus welckeri (Chlorophyta, Ulvophyceae). BMC Evolutionary Biology 10:1-12.

Theil, H. 1950. A rank-invariant method of linear and polynomial regression analysis, I, II, III. Proceedings of the Koninklijke Nederlandse Akademie Wetenschappen, Series A: Mathematical Sciences 53:386-392.

Tierney, J. E., M. T. Mayes, N. Meyer, C. Johnson, P. W. Swarzenski, A. S. Cohen, and J. M. Russell. 2010. Late-twentiethcentury warming in Lake Tanganyika unprecedented since AD 500. Nature Geoscience 3:422-425.
Tobias, C., and J. Böhlke. 2007. The oxygen-18 isotope approach for measuring aquatic metabolism in high productivity waters. Limnology and Oceanography 52:1439-1453.

Trussell, G. C., P. J. Ewanchuk, and M. D. Bertness. 2003. Traitmediated effects in rocky intertidal food chains: predator risk cues alter prey feeding rates. Ecology 84:629-640.

Vadeboncoeur, Y., S. P. Devlin, P. B. McIntyre, and M. J. Vander Zanden. 2014. Is there light after depth? Distribution of periphyton chlorophyll and productivity in lake littoral zones. Freshwater Science 33:524-536.

Vadeboncoeur, Y., P. B. McIntyre, and M. J. Vander Zanden. 2011. Borders of biodiversity: life at the edge of the world's large lakes. BioScience 61:526-537.

West, K., and A. Cohen. 1994. Predator-prey coevolution as a model for the unusual morphologies of the crabs and gastropods of Lake Tanganyika. Archiv für Hydrobiologie-Beiheft Ergebnisse der Limnologie 44:267-283.

West, K., and A. Cohen. 1996. Shell microstructure of gastropods from Lake Tanganyika, Africa: adaptation, convergent evolution, and escalation. Evolution 50:672-681.

West, K., A. Cohen, and M. Baron. 1991. Morphology and behavior of crabs and gastropods from Lake Tanganyika, Africa: implications for lacustrine predator-prey coevolution. Evolution 45:589-607.

West, K., and E. Michel. 2000. The dynamics of endemic diversification: molecular phylogeny suggests an explosive origin of the thiarid gastropods of Lake Tanganyika. Advances in Ecological Research 31:331-354.

West, K., E. Michel, J. A. Todd, D. S. Brown, and J. Clabaugh. 2003. The gastropods of Lake Tanganyika: diagnostic key and taxonomic classification with notes on the fauna. International Association of Theoretical and Applied Limnology: Occasional Publications 2:1-132.

Yvon-Durocher, G., J. I. Jones, M. Trimmer, G. Woodward, and J. M. Montoya. 2010. Warming alters the metabolic balance of ecosystems. Philosophical Transactions of the Roval Society of London Series B: Biological Sciences 365:2117-2126. 